\title{
Pola Perjalanan Penduduk Pinggiran Menuju Kota Surakarta Ditinjau Dari ASPEK Spasial Dan ASPEK ASPaSial
}

\author{
Kharisma Narendra Aditama, Soedwiwahjono, Rufia Andisetyana Putri \\ Program Studi Perencanaan Wilayah dan Kota, \\ Fakultas Teknik \\ Universitas Sebelas Maret, Surakarta \\ email: kharisma.narendra@yahoo.com
}

\begin{abstract}
The city of Surakarta as a region which continues to undergo development has become an attraction for residents around the city core. Surakarta City which was originally not crowded will developed rapidly into densely populated area, impact of the process of trip that conducted by trip doers from suburban to the city core in particular. This would cause due to increasing interaction between suburban area with city core which also have impacts on traffic and population density especially for Surakarta as the city core.

This research was conducted to know the characteristics of the trip patterns of suburban residents to Surakarta City so it will be described how the process of trip conducted by suburban residents to Surakarta City, and from that process of trip can be known proper management to overcome problems especially the transportation problems in Surakarta City and the surrounding areas. This research included in descriptive research which illustrates and describes a specific condition from the certain object, in this case will be portrayed in descriptive how the characteristics of the process of trip conducted by suburban residents that happened.

The result of this research is based on the purpose of trip dominated by the purpose to working at $47 \%$ residents followed by the purpose to education at $27 \%$ and the purpose to shopping at $26 \%$. Then based on income level dominated by residents with income level less than 1.145.000 rupiah, majority of residents already have private vehicles and age of trip doers dominated by 15-40 years regarded as productive age. Based on trip distribution is known that land use domination in Surakarta City is trade and services, and based on route march dominated by people pass the south area of Surakarta City and this case will trigger traffic density and the changes of space function in region of Surakarta City.
\end{abstract}

Keywords: regional interaction, trip characteristics, trip patterns, descriptive research

\section{PENDAHULUAN}

Kota Surakarta sebagai kota humanis diharapkan mampu menjadi kota yang nyaman bagi penduduknya. Berardus (dalam Dewi, et, al. 2014. http://bisnisnews.viva.co.id/news/read/528082ini -kota-paling-layak-huni-di-indonesia) mengatakan bahwa menurut hasil survey yang dilakukan Ikatan Ahli Perencanaan Indonesia pada tahun 2014 mengenai most liveable city index di Indonesia, Kota Surakarta termasuk ke dalam kota kedua yang layak huni di Indonesia. Namun dengan pesatnya perkembangan Kota Surakarta yang pesat telah memicu permasalahan yang dapat merusak citra Kota Surakarta sebagai kota humanis. Kota Surakarta saat ini telah mengalami perubahanperubahan yang membuat identitas humanis dari kota ini semakin memudar. Hal tersebut dibuktikan dengan semakin padatnya penduduk akibat dari peningkatan kegiatan yang terjadi di Kota Surakarta.
Kota Surakarta saat ini dirasa cukup sukses dengan roda perekonomian dari berbagai kalangan, di mana kegiatan ekonomi di kota ini terlihat terus berkembang. Hal ini dapat dilihat dari semakin banyaknya bangunan-bangunan baik untuk industri, perdagangan, permukiman maupun yang lainnya. Selain itu dengan tingginya tingkat pertumbuhan ekonomi, Kota Surakarta juga menyediakan lapangan pekerjaan yang cukup luas di berbagai bidang.

Di sisi lain dengan semakin beragam dan banyaknya kegiatan yang terjadi di dalam kota menuntut kelengkapan fasilitas kota yang juga mampu melayani kawasan di sekitarnya seperti fasilitas pendidikan, kesehatan, atau pun fasilitas sosial lainnya (Pontoh, et al. 2009). Pada akhirnya hal tersebut menjadikan Kota Surakarta sebagai pusat pertumbuhan bagi wilayah sekitarnya, di mana daerah pinggiran memiliki kedekatan lokasi dengan Kota Surakarta yang akan berdampak pada 
tingginya proses perjalanan yang terjadi, terutama perjalanan yang dilakukan dengan intensitas tinggi. Seperti yang dikatakan Spiro Kostof (dalam Soetomo, 2009) bahwa kota merupakan tempat yang terbentuk tidak hanya oleh bangunan saja namun juga oleh manusianya, artinya manusia dapat dikatakan sebagai aktor utama yang menentukan bagaimana pertumbuhan dan perkembangan yang terjadi pada suatu kota.

Dari proses perkembangannya terdapat permasalahan baru yang muncul akibat semakin tingginya intensitas kegiatan yang dilakukan pada kota ini, masalah tersebut salah satunya adalah semakin padatnya penduduk di daerah kota. Apabila dilihat dari sisi penduduk, jumlah penduduk Kota Surakarta pada malam hari sekitar 542.000 jiwa, namun pada siang hari dapat mencapai 2 juta jiwa (Suara Merdeka, 2014), selain itu volume kendaraan di Kota Surakarta pada siang hari dapat bertambah hingga empat kali lipat dibandingkan pada pagi dan malam hari.

Kota Surakarta sendiri sebagai daerah yang mampu melayani kawasan-kawasan pinggiran di sekitarnya juga menjadi tujuan utama dari perjalanan penduduk pinggiran. Kota Surakarta memiliki kelengkapan fasilitas kota yang sangat lengkap dilihat dari jumlah dan jenis fasilitas yang disediakan. Hal tersebut secara tersirat menjadikan Kota Surakarta sebagai pusat tujuan pergerakan wilayah-wilayah pinggiran di sekitarnya dengan tujuan yang beragam, sehingga hal tersebut mengakibatkan semakin besarnya perjalanan penduduk pinggiran menuju kota inti.

Perjalanan penduduk pinggiran menuju Kota Surakarta ini terjadi dengan berbagai macam tujuan dan perilaku yang beragam, sehingga dengan diketahuinya keberagaman dari karakteristik perjalanan penduduk pinggiran menuju Kota Surakarta, akan diketahui permasalahan-permasalahan yang terjadi akibat dari proses perjalanan yang dihasilkan oleh para penduduk pinggiran menuju Kota Surakarta

Mengacu pada hal di atas, maka rumusan permasalahan dalam penelitian ini adalah bagaimana pola perjalanan penduduk pinggiran menuju Kota Surakarta yang dilihat dari beberapa aspek penting.

\section{METODE PENELITIAN}

Penelitian ini termasuk ke dalam penelitian deskriptif yang mencoba menggambarkan dan mendeskripsikan suatu kondisi yang spesifik dari suatu objek tertentu (Creswell, 2010) dalam hal ini akan digali terkait pola perjalanan yang dilihat berdasarkan karakteristik pelaku, perilaku dan sebaran perjalanan penduduk pinggiran menuju Kota Surakarta. Penelitian terkait pola perjalanan penduduk ini masuk ke dalam penelitian kuantitatif karena penelitian ini bersifat menguji teori-teori tertentu.

Dalam pengumpulan data yang dibutuhkan dalam penelitian terbagi menjadi data primer dan data sekunder. Data primer didapatkan melalui observasi lapangan, wawancara dan kuesioner serta data sekunder didapatkan melalui studi dokumen/literatur dan interpretasi peta.

Teknik analisis yang digunakan dalam penelitian ini secara garis besar menggunakan analisis secara deskriptif kuantitatif dan spasial. Penelitian ini merupakan penelitian studi kasus dengan metoda observasi langsung ke lapangan kemudian di proses menggunakan analisis deskriptif kuantitatif dan spasial. Analisis yang digunakan terdiri dari tiga tahapan yaitu:

1. Mengidentifikasi karakteristik pelaku perjalanan penduduk pinggiran kota

2. Mengidentifikasi karakteristik perilaku perjalanan penduduk pinggiran kota

3. Mengidentifikasi sebaran perjalanan penduduk pinggiran menuju kota

4. Menganalisis pola perjalanan aspasial penduduk pinggiran menuju Kota Surakarta

5. Menganalisis pola perjalanan spasial penduduk pinggiran menuju Kota Surakarta

\section{HASIL DAN PEMBAHASAN}

A. Pola Perjalanan Aspasial Penduduk Pinggiran menuju Kota Surakarta

Pola perjalanan aspasial dilihat dari beberapa aspek yaitu usia, tingkat pendapatan, kepemilikan kendaraan, jarak perjalanan, waktu perjalanan, tujuan perjalanan, dan moda yang digunakan (Jamal, 2014).

Dari hasil analisis diketahui bahwa penduduk pinggiran menuju Kota Surakarta dengan usia antara 15-40 tahun, dengan tingkat pendapatan yang relatif masih rendah, namun telah memiliki kendaraan pribadi dalam 
melaukan perjalanan lebih mendominasi dengan menunjukan perilaku di mana penduduk dengan karakteristik tersebut lebih memilih melakukan perjalanan dengan jarak yang relatif dekat dengan daerah asal, dilakukan pada waktu sibuk antara pagi hingga siang hari, dan dilakukan dengan kendaraan pribadi baik berupa sepeda motor ataupun mobil. Selain itu dominasi tujuan penduduk melakukan perjalanan yaitu bekerja.

Dapat dikatakan bahwa penduduk pinggiran yang menuju Kota Surakarta merupakan penduduk yang masuk dalam kategori usia produktif namun masih mengharapkan tingkat pendapatan yang lebih menjanjikan di kota inti karena itulah penduduk lebih memilih melakukan perjalanan bekerja menuju kota, maka dengan segala keterbatasan tersebut penduduk pinggiran memilih melakukan perjalanan dengan jarak yang relatif dekat dengan menggunakan kendaraan pribadi dengan pertimbangan mampu menghemat biaya perjalanan.

Selanjutnya yang menjadi perhatian adalah bagaimana kondisi yang terdapat di lapangan bahwa penggunaan kendaraan lebih didominasi dengan moda transportasi pribadi. Dari kondisi tersebut dapat dikatakan bahwa minat penduduk untuk menggunakan moda transportasi umum sangatlah minim, anggapan bahwa kendaraan pribadi merupakan moda yang paling efektif dalam melakukan perjalanan menjadikan penduduk berusaha untuk memiliki kendaraan pribadi (Pratama, 2012), dan hal tersebut akan berujung pada permasalahan kepadatan lalu lintas khususnya bagi daerah Kota Surakarta sebagai daerah tujuan penduduk pinggiran dalam melakukan kegiatan.

B. Perjalanan Penduduk Spasial Penduduk Pinggiran menuju Kota Surakarta.

Pola perjalanan spasial dilihat dari identifikasi sebaran perjalanan dengan melihat daerah asal dan tujuan untuk kemudian juga dilihat berdasarkan penggunaan lahan pada daerah tujuan (Tamin, 1997) yaitu Kota Surakarta.
Dari hasil analisis tergambarkan pola perjalanan berdasarkan sebaran perjalanan yang terbentuk dari perilaku para pelaku perjalanan penduduk di pinggiran Kota Surakarta dapat diketahui bahwa, tercatat sebesar $47 \%$ penduduk pinggiran melakukan kegiatan bekerja di kota, sebesar 27\% penduduk melakukan kegiatan pendidikan, dan sebesar $26 \%$ penduduk melakukan kegiatan belanja di kota. Kegiatankegiatan ini secara keruangan memang menyebar diberbagai lokasi di Kota Surakarta, namun juga membentuk pola sebaran tertentu yaitu dengan dominasi sebaran tujuan perjalanan di jalan utama atau kawasan perdagangan dan jasa. Hal di atas dapat digambarkan pada peta sebaran perjalanan (dilihat pada Lampiran 1).

Berdasarkan pola perjalanan yang paling banyak dikunjungi penduduk pinggiran Kota Surakarta adalah kawasan tengah dan selatan bagian Kota Surakarta, di antaranya terdapat titik-titik yang paling ramai yaitu Jalan Slamet Riyadi, Jalan Yosodipuro, Kelurahan Manahan dan Kelurahan Jebres di mana kawasan ini merupakan kawasan yang dipenuhi kegiatan perdagangan dan jasa yang selain merupakan tempat tujuan berbelanja juga merupakan kawasan dengan jumlah pekerja yang besar. Selain itu untuk kegiatan pendidikan, penduduk pinggiran Kota Surakarta mayoritas melakukan perjalanan ke kampus UNS, dan Unisri serta kebeberapa kawasan pendidikan lain di Jalan Monginsidi. Hal di atas dapat digambarkan pada peta pola perjalanan (dilihat pada Lampiran 2).

\section{KESIMPULAN}

Berdasarkan penjelasan mengenai pola perjalanan di atas, maka dapat diindikasikan bahwa fasilitas yang terdapat di Kota Surakarta memang masih menjadi daya tarik utama penduduk pinggiran dengan berbagai macam karakteristik untuk memenuhi kebutuhan hidupnya, selain juga karena fasilitas di pinggiran belum mampu melayani dan memfasilitasi kebutuhan penduduk sekitarnya.

Selain itu dari proses penelitian ini pada akhirnya dapat diketahui bahwa proses perjalanan yang dilakukan para penduduk pinggiran menuju Kota Surakarta dengan berbagai karakteristik menjadi salah satu 
penyebab permasalahan kepadatan dan kemacetan lalu lintas pada ruas-ruas jalan terutama ruas jalan penghubung antara wilayah pinggiran kota dengan Kota Surakarta sebagai kota inti. Untuk lebih jelas maka digambarkan berupa skema pola perjalanan penduduk pinggiran menju Kota Surakarta. (dilihat pada Lampiran 3 dan 4).

\section{REFERENSI}

Creswell, John, 2010. Research Design Pendekatan Kualitatif, kuantitatif dan Mixed. Yogyakarta: Pustaka Pelajar.

Jamal, Ferdian, 2014, Pengaruh karakteristik zona permukiman terhadap pemilihan jenis moda transportasi yang digunakan masyarakat untuk kegiatan bekerjanya sehari-hari di Kecamatan Sagulung, Kota Batam. Semarang: UNDIP.

Pontoh, Nia K, et al. 2009. Pengantar Perencanaan Perkotaan. Bandung: Institut Teknologi Bandung.

Pratama, Rizky, 2012. Preferensi pemilihan moda dalam pergerakan penglaku koridor Bogor-Jakarta terkait dengan pemilihan tempat tinggal, Jurnal PWK, vol. 23, No. 1

Soetomo, Sugiono, 2009. Urbanisasi dan Morfologi. Graha ilmu.

Tamin, Ofyar, 1997. Perencanaan dan Pemodelan Transportasi. Bandung: Institut Teknologi Bandung.

Suara Merdeka, 2014. Solo Metro.

\section{REFERENSI WEB}

Berardus (dalam Dewi, et, al. 2014). Kota Paling Layak Huni di Indonesia. From http:/bisnisnews.viva.co.id/news/read/528082-ini kota-paling-layak-huni-di-indonesia, 24Mei 2015 


\section{LAMPIRAN}

Lampiran 1. Peta Sebaran Perjalanan Penduduk Pinggiran Menuju Kota Surakarta

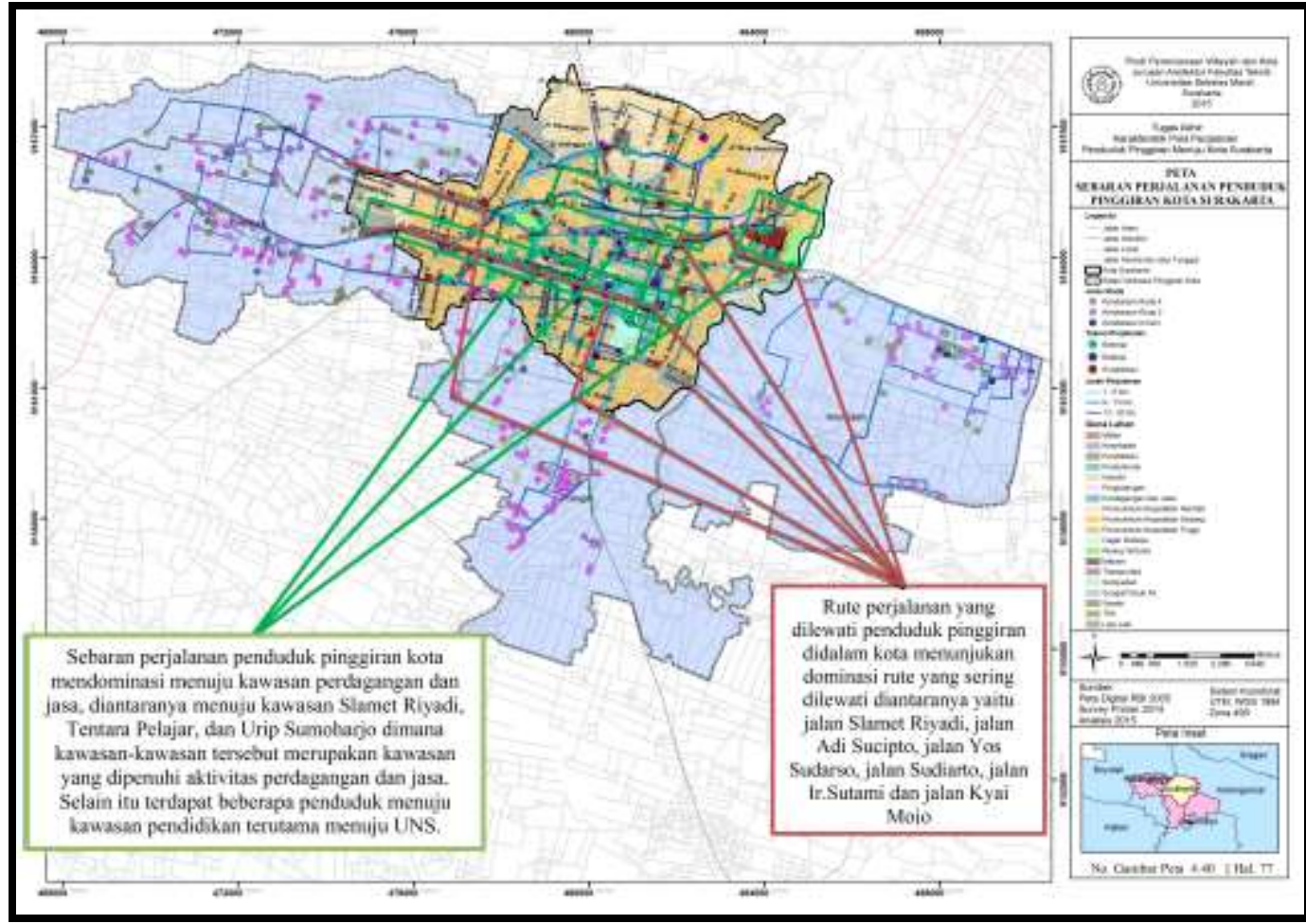

Sumber: Peta Digital RBI 2005, Survey Primer 2014, Analisis 2015

Lampiran 2. Peta Pola Perjalanan Penduduk Pinggiran Menuju Kota Surakarta

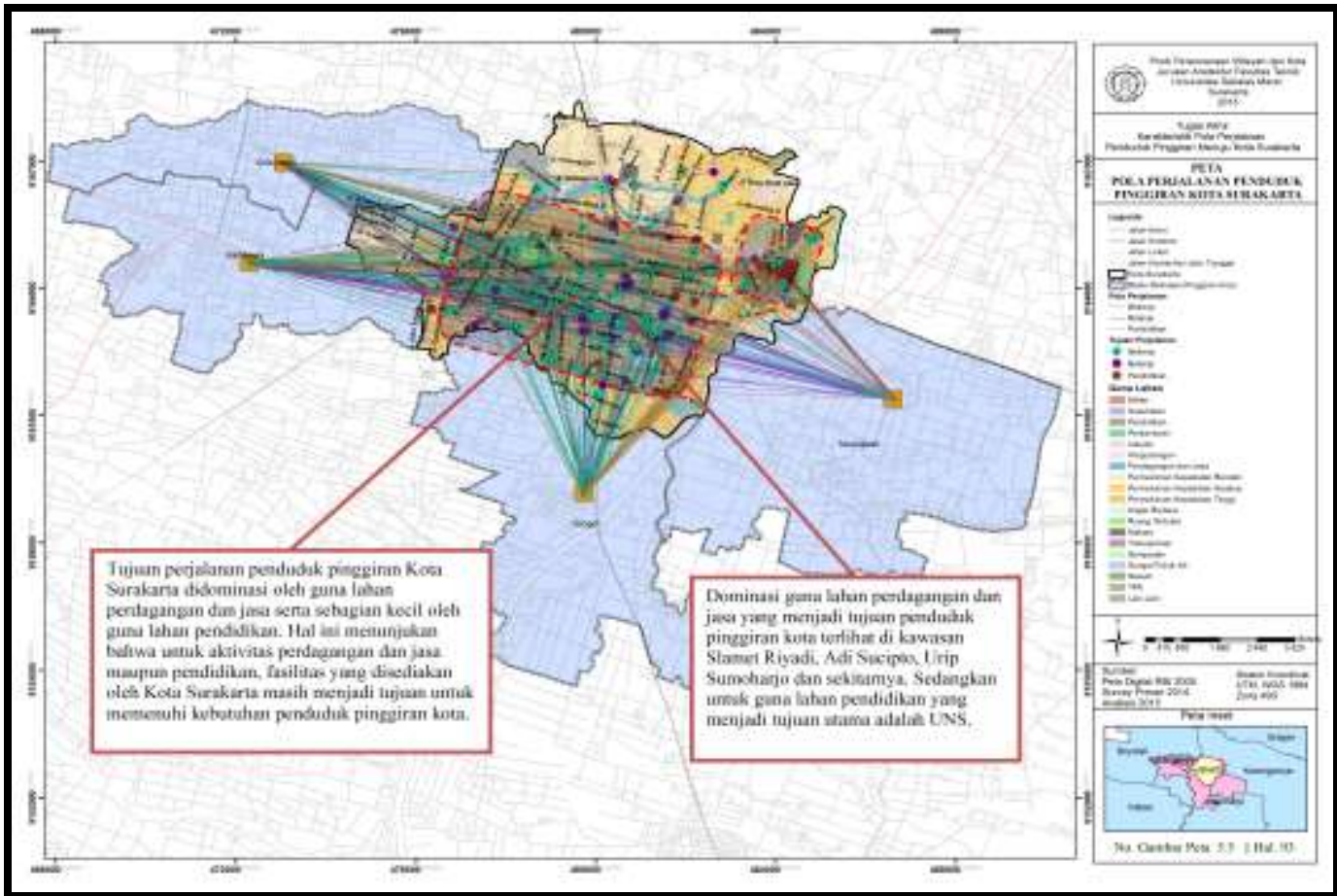

Sumber: Peta Digital RBI 2005, Survey Primer 2014, Analisis 2015 


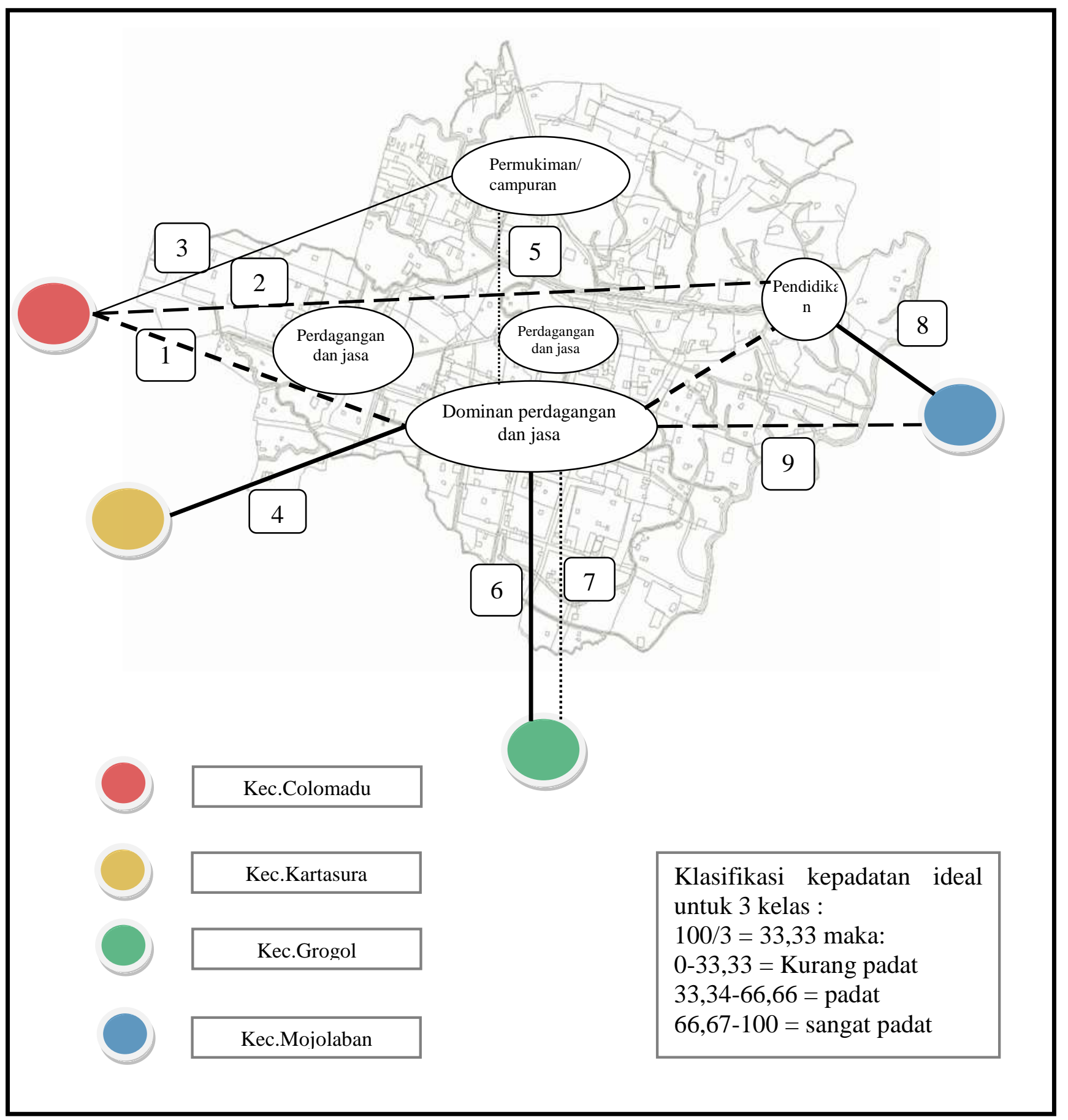

Sumber: Survey Primer 2014, Analisis 2015 
Kharisma Narendra A, Soedwiwahjono, Rufia Andisetyana P, Pola Perjalanan Pemduduk....

Lampiran 4. Tabel Kepadatan Rute Perjalanan Penduduk Pinggiran Kota Menuju Kota Surakarta

\begin{tabular}{|c|c|c|c|c|c|c|c|}
\hline No & $\begin{array}{c}\text { Kecamatan } \\
\text { asal }\end{array}$ & $\begin{array}{c}\text { Rute jalan yang } \\
\text { dilewati }\end{array}$ & $\begin{array}{l}\text { No } \\
\text { rute }\end{array}$ & $\begin{array}{c}\text { Kepadatan } \\
\text { rute yang } \\
\text { dilewati } \\
\%\end{array}$ & $\begin{array}{l}\text { Klasifikasi } \\
\text { kepadatan } \\
\text { rute }\end{array}$ & $\begin{array}{c}\text { Tujuan } \\
\text { Perjalanan }\end{array}$ & $\begin{array}{c}\text { Kepadatan rute } \\
\text { berdasarkan } \\
\text { tujuan } \\
\text { perjalanan } \\
\%\end{array}$ \\
\hline \multirow{9}{*}{1} & \multirow{9}{*}{ Colomadu } & \multirow{3}{*}{$\begin{array}{l}\text { Jalan Adisucipto- } \\
\text { Slamet Riyadi }\end{array}$} & \multirow{3}{*}{1} & \multirow{3}{*}{56,7} & \multirow{3}{*}{ Padat } & Bekerja & 28,9 \\
\hline & & & & & & Berbelanja & 15,5 \\
\hline & & & & & & Pendidikan & 12,4 \\
\hline & & \multirow{3}{*}{$\begin{array}{l}\text { Jalan Adisucipto- } \\
\text { Tentara Pelajar }\end{array}$} & \multirow{3}{*}{2} & \multirow{3}{*}{34,02} & \multirow{3}{*}{ Padat } & Bekerja & 18,6 \\
\hline & & & & & & Berbelanja & 4,1 \\
\hline & & & & & & Pendidikan & 11,3 \\
\hline & & \multirow{3}{*}{$\begin{array}{l}\text { Jalan Adisucipto- } \\
\text { Letnan Suprapto }\end{array}$} & \multirow{3}{*}{3} & \multirow{3}{*}{9,28} & \multirow{3}{*}{ Kurang padat } & Bekerja & 6,2 \\
\hline & & & & & & Berbelanja & 1,0 \\
\hline & & & & & & Pendidikan & 2,1 \\
\hline \multirow{6}{*}{2} & \multirow{6}{*}{ Kartasura } & \multirow{3}{*}{$\begin{array}{l}\text { Slamet Riyadi- } \\
\text { Urip Sumoharjo- } \\
\text { Ir Sutami }\end{array}$} & \multirow{3}{*}{4} & \multirow{3}{*}{67,01} & \multirow{3}{*}{ Sangat padat } & Bekerja & 21,6 \\
\hline & & & & & & Berbelanja & 20,6 \\
\hline & & & & & & Pendidikan & 24,7 \\
\hline & & \multirow{3}{*}{$\begin{array}{l}\text { Slamet Riyadi- } \\
\text { Tentara Pelajar- } \\
\text { Sugiono }\end{array}$} & \multirow{3}{*}{5} & \multirow{3}{*}{32,99} & \multirow{3}{*}{ Kurang padat } & Bekerja & 25,8 \\
\hline & & & & & & Berbelanja & 0,0 \\
\hline & & & & & & Pendidikan & 7,2 \\
\hline \multirow{6}{*}{3} & \multirow{6}{*}{ Grogol } & \multirow{3}{*}{$\begin{array}{l}\text { Yos Sudarso- } \\
\text { Slamet Riyadi }\end{array}$} & \multirow{3}{*}{6} & \multirow{3}{*}{75,93} & \multirow{3}{*}{ Sangat padat } & Bekerja & 54,6 \\
\hline & & & & & & Berbelanja & 10,2 \\
\hline & & & & & & Pendidikan & 11,1 \\
\hline & & \multirow{3}{*}{$\begin{array}{c}\text { Sudiarto- Kapten } \\
\text { Mulyadi }\end{array}$} & & & & Bekerja & 4,6 \\
\hline & & & 7 & 24,07 & Kurang padat & Berbelanja & 0,0 \\
\hline & & & & & & Pendidikan & 19,4 \\
\hline & & & & & & Bekerja & 37,5 \\
\hline & & Ir Sutami-Urip & 8 & 59,71 & Padat & Berbelanja & 9,7 \\
\hline 4 & & Sumonarjo & & & & Pendidikan & 12,5 \\
\hline 4 & Mojolaban & & & & & Bekerja & 15,3 \\
\hline & & $\begin{array}{l}\text { Kyai Mojo- } \\
\text { Slamet Rivadi }\end{array}$ & 9 & 40,28 & Padat & Berbelanja & 23,6 \\
\hline & & Slamet Riyadı & & & & Pendidikan & 1,4 \\
\hline
\end{tabular}

Sumber: Analisis 2015 